\title{
DRH and Reversible Non-Deliquescent Water Uptake in the Sodium Salts of Succinic Acid
}

Keith D. Beyer ${ }^{*}$

Department of Chemistry and Biochemistry, University of Wisconsin-La Crosse, La Crosse, WI 54601 
Supporting Information

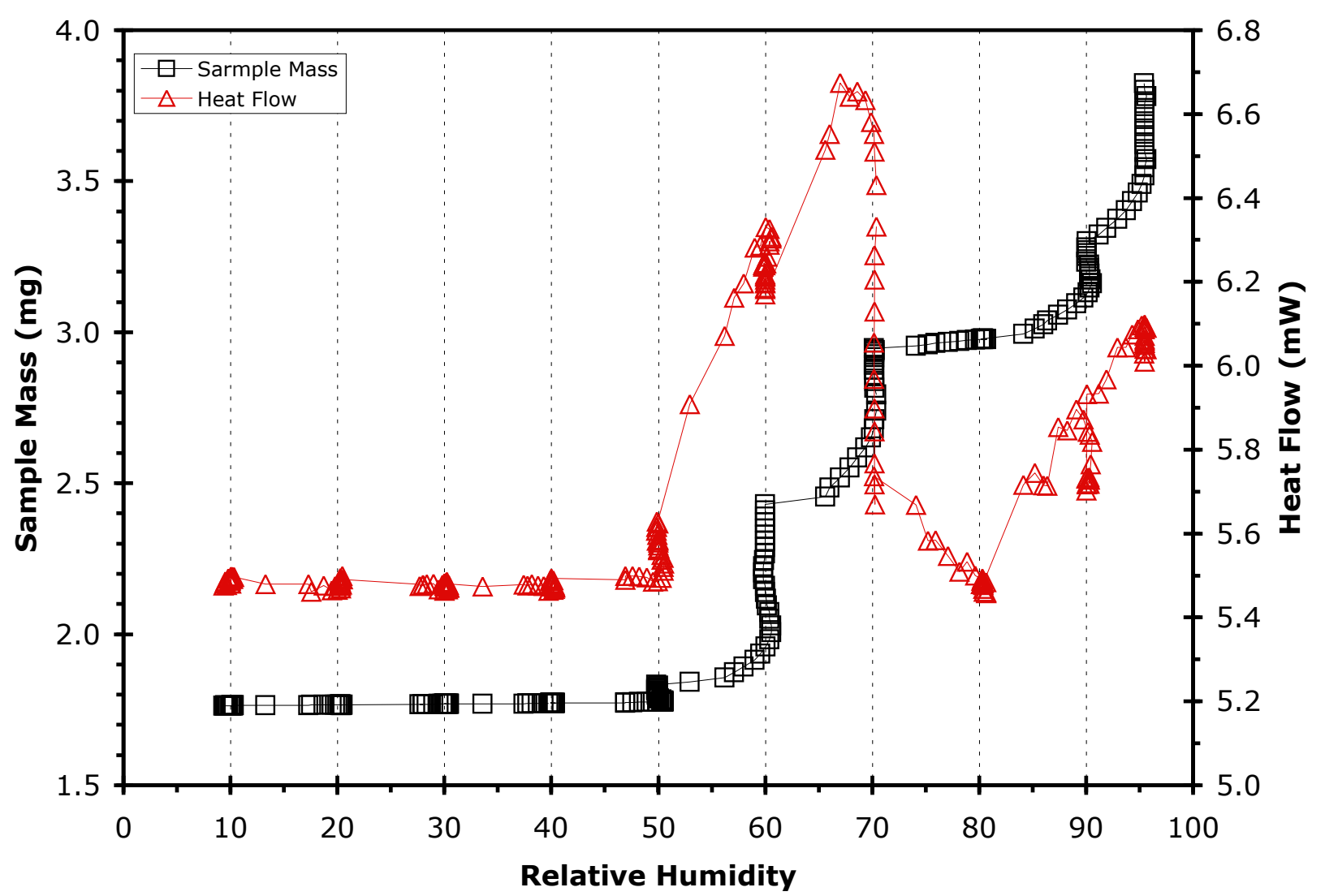

Figure S1. Alternate plot of mass and heat flow for a dry $\mathrm{Na}_{2} \mathrm{C}_{4} \mathrm{H}_{4} \mathrm{O}_{4}$ sample as a function of Relative Humidity (RH) at 298.1 K from 10 to $95 \%$ RH (same data as Figure 2). An increase in sample mass accompanied by heat from the sample (increase in heat flow) indicates water uptake by the sample. 


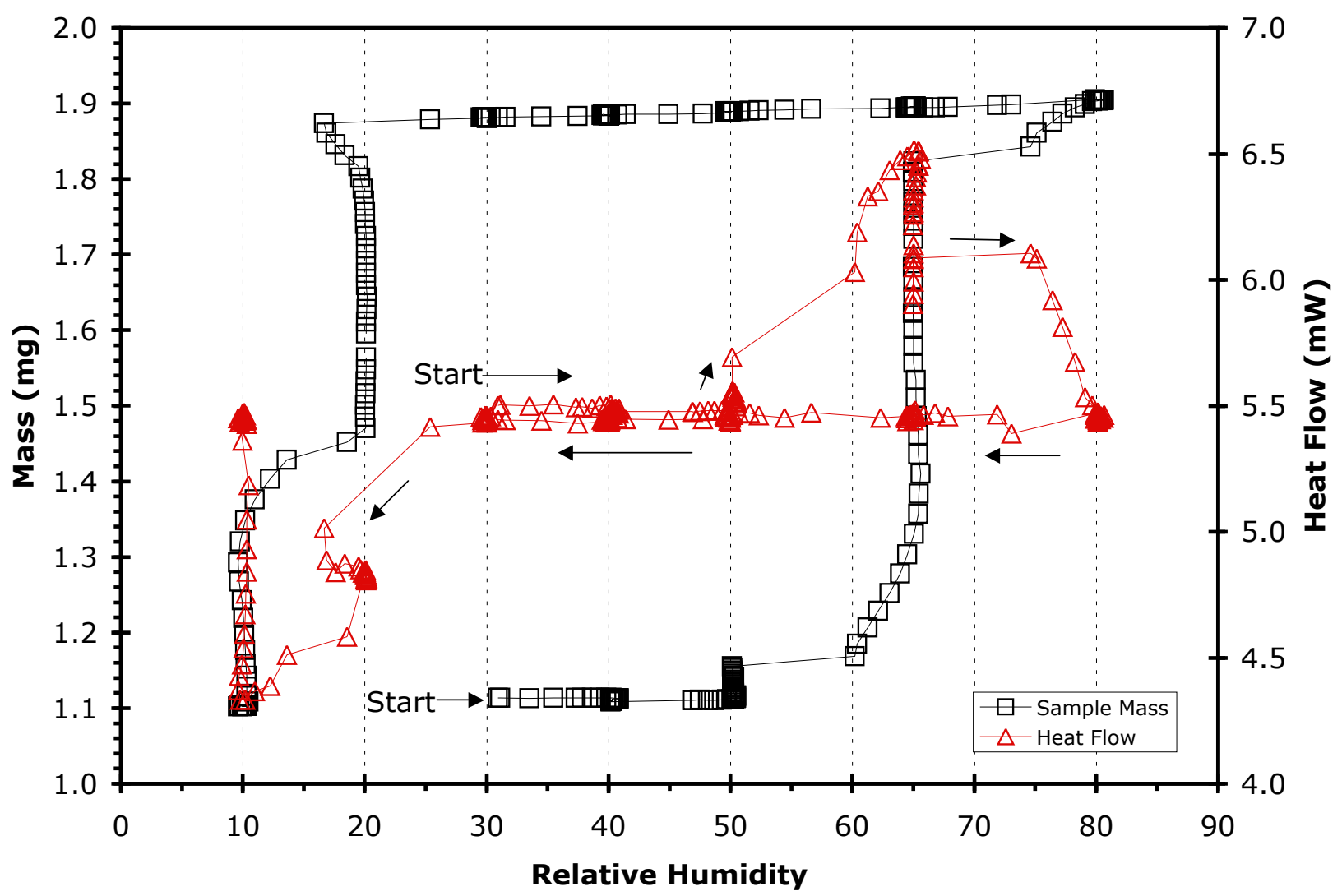

Figure S2. Alternate plot of mass and heat flow for a dry $\mathrm{Na}_{2} \mathrm{C}_{4} \mathrm{H}_{4} \mathrm{O}_{4}$ sample as a function of Relative Humidity (RH) at $298.3 \mathrm{~K}$ (same data as Figure 3). Arrows indicate the start of the experiment at $30 \% \mathrm{RH}$ and subsequent increase in $\mathrm{RH}$ in steps up to $80 \% \mathrm{RH}$, then decrease in steps to $10 \% \mathrm{RH}$. Connecting lines show the path of the experiment. Arrows also indicate the experiment path for the Heat Flow signal since many data points are coincident. 
Supporting Information

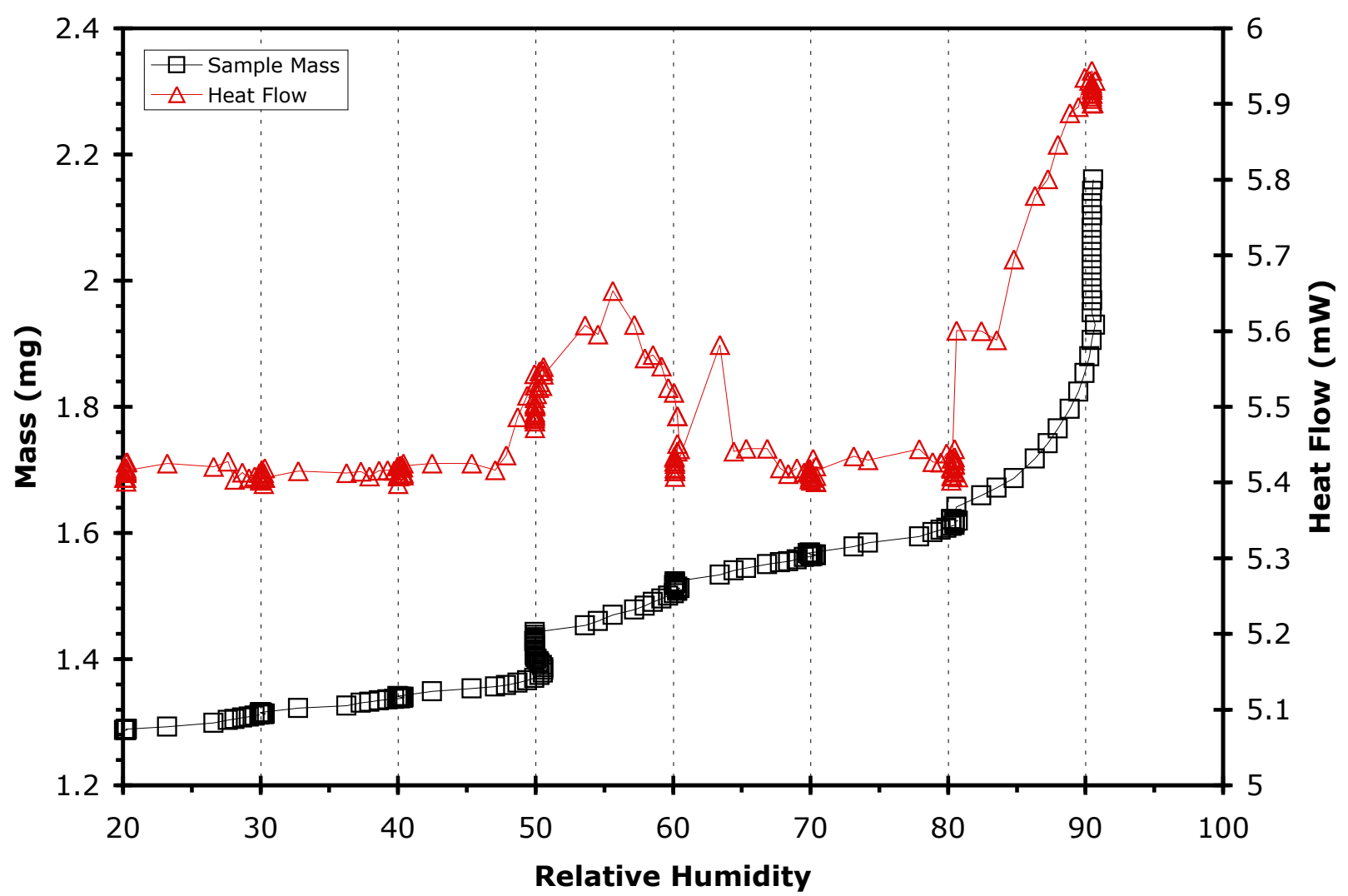

Figure S3. Alternate plot of mass and heat flow for a dry $\mathrm{NaHC}_{4} \mathrm{H}_{4} \mathrm{O}_{4}$ sample as a function of Relative Humidity (RH) at $298.1 \mathrm{~K}$ from 10 to $90 \% \mathrm{RH}$ (same data as in Figure 5). An increase in sample mass accompanied by heat from the sample (increase in heat flow) indicates water uptake by the sample. 


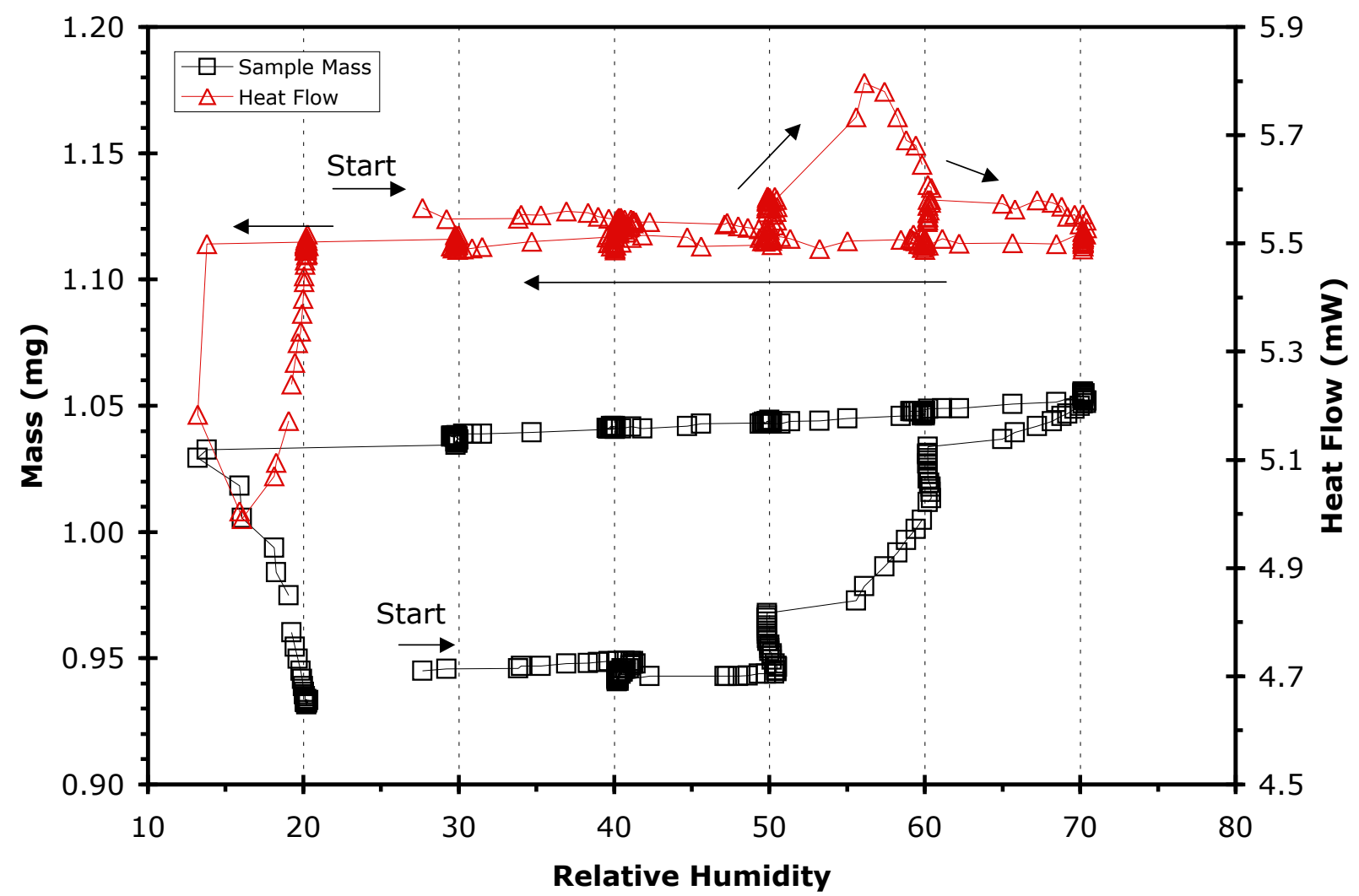

Figure S4. Alternate plot of mass and heat flow for a dry $\mathrm{NaHC}_{4} \mathrm{H}_{4} \mathrm{O}_{4}$ sample as a function of Relative Humidity (RH) at 298.2 K (same data as in Figure 6). Arrows indicate the start of the experiment at $27 \% \mathrm{RH}$ and subsequent increase in $\mathrm{RH}$ in steps up to $70 \% \mathrm{RH}$, then decrease in steps to $20 \% \mathrm{RH}$. Connecting lines show the path of the experiment. Arrows also indicate the experiment path for the Heat Flow signal since many data points are coincident. 